\title{
Phytophthora-ID.org: A Sequence-Based Phytophthora Identification Tool
}

\author{
Niklaus J. Grünwald, Horticultural Crops Research Laboratory, United States Department of Agriculture-Agricultural Research Ser- \\ vice (USDA-ARS), Corvallis, OR 97330; Frank N. Martin, Crop Improvement of Protection Research Unit, USDA-ARS, Salinas, CA \\ 93905; Meredith M. Larsen, Horticultural Crops Research Laboratory, USDA-ARS; Christopher M. Sullivan, Center for Genome \\ Research and Biocomputing, Oregon State University, Corvallis 97331; Caroline M. Press, Horticultural Crops Research Laboratory, \\ USDA-ARS; Michael D. Coffey, Department of Plant Pathology, University of California, Riverside 92521; and Everett M. Hansen \\ and Jennifer L. Parke, Department of Botany and Plant Pathology, Oregon State University, Corvallis
}

\begin{abstract}
Grünwald, N. J., Martin, F. N., Larsen, M. M., Sullivan, C. M., Press, C. M., Coffey, M. D., Hansen, E. M., and Parke, J. L. 2011. PhytophthoraID.org: A sequence-based Phytophthora identification tool. Plant Dis. 95:337-342.

Contemporary species identification relies strongly on sequence-based identification, yet resources for identification of many fungal and oomycete pathogens are rare. We developed two web-based, searchable databases for rapid identification of Phytophthora spp. based on sequencing of the internal transcribed spacer (ITS) or the cytochrome oxidase (cox) 1 and 2 spacer region, followed by BLAST searching the databases. Both databases are highly selective. For ITS, only sequences associated with published Phytophthora spp. descriptions or classic

spacer region, only data obtained by resequencing select isolates reported in published work were included. Novel taxa tentatively named are selectively included in the database and labeled as Phytophthora taxon "X"; as in, for example, $P$. taxon "asparagi". The database was validated with 700 Phytophthora isolates collected from nursery environments during 2006 to 2009. This resource, found at www. Phytophthora-ID.org, is a robust and validated tool for molecular identification of Phytophthora spp. and is regularly being updated.
\end{abstract} Phytophthora phylogenetics references are included. For the cox
Contemporary species identification relies strongly on sequencebased identification, yet resources for identifying many fungal and oomycete pathogens are rare. The genus Phytophthora houses some of the most destructive plant pathogens known, including, for example, the potato late blight pathogen Phytophthora infestans $(10,11)$; the sudden oak death pathogen $P$. ramorum $(17,31)$; and $P$. cinnamomi, a pathogen affecting in excess of 3,000 species of plants, including over 2,500 Australian native species and crops such as avocado, pineapple, peach, chestnut, and macadamia (19). Since the discovery of $P$. ramorum in the late 1990 s, renewed interest in Phytophthora biology has led to the discovery of many new Phytophthora spp. In 1996, approximately 60 species of Phytophthora were known to science (7). By 2008, around 90 species of Phytophthora were described or proposed. In fact, Brasier (3) estimated that we might expect two to four times that number of Phytophthora spp. to be described. Given the rapid discovery of novel species, an increase in the number of species of regulatory

Corresponding author: N. J. Grünwald

E-mail: grunwaln@science.oregonstate.edu

Mentions of trade names or commercial products in this manuscript are solely for the purpose of providing specific information and do not imply recommendation or endorsement by the United States Department of Agriculture.

* The $\boldsymbol{e}$-Xtra logo stands for "electronic extra" and indicates that two supplemental tables appear online and that Figures 1, 2, and 3 appear in color in the online edition.

Accepted for publication 25 October 2010.

doi:10.1094/PDIS-08-10-0609

This article is in the public domain and not copyrightable. It may be freely reprinted with customary crediting of the source. The American Phytopathological Society, 2011. concern, and the prevalence of encountering Phytophthora spp. in diagnostic labs, a contemporary tool for identification of Phytophthora isolates to a species level is urgently needed.

A tool for rapid and easy identification of Phytophthora spp. would have to fulfill several requirements. Ideally, this tool should be sequence based because classical morphology is unable to distinguish many of the species currently recognized. For example $P$. infestans, $P$. ipomoeae, and $P$. mirabilis cannot easily be distinguished based on morphology alone because these species are essentially identical for sporangia (semipapillate and caducous) and oospore morphology $(7,8,12)$. Yet, analysis of several sequences clearly distinguishes these species (8). A contemporary Phytophthora spp. identification tool also should be robust enough so that most laboratories with a thermocycler, basic molecular capability, and web access could make use of it.

Traditionally, molecular identification of Phytophthora spp. is accomplished by polymerase chain reaction (PCR) amplification of the internal transcribed spacer (ITS) region followed by either restriction analysis (5) or direct sequencing and a BLAST search against GenBank or other databases. However, molecular identification based on the ITS region is not without its pitfalls (23). Although PCR-restricted fragment length polymorphism (RFLP) analysis of the ITS region can identify many species, currently, data for only one-half of the described species are available, and there are examples where ITS PCR-RFLP is not effective for differentiating closely related species (e.g., clade $1 \mathrm{c}$ species such as $P$. infestans and $P$. mirabilis). Identification can also be a challenge when using BLAST analysis with ITS sequences because there can be minimal or no differences between some species (e.g., clade 1c species) or, in some cases, intraspecific variation can blur the boundaries between species (e.g., $P$. fragariae var. fragariae and $P$. fragariae var. rubi have identical ITS sequences). Due to its historical importance for the identification and phylogenetic analysis of the genus and the large number of sequences that have been deposited in GenBank, the ITS region remains an important locus for molecular identification; however, additional regions also have 
been examined $(2,24,28,32)$. As more sequence data is collected from a wider range of geographically diverse isolates, the utility of alternative loci for accurate species identification will increase.

Perhaps the most important component for accurate molecular identification to the species level is the underlying database that is used. BLAST searches can be challenging once databases accumulate sequences that are mislabeled, of poor quality, or otherwise problematic (23). Thus, good reference libraries for identification of microorganisms need to be curated for quality. As of 26 March 2009, GenBank contained 47,794 Phytophthora DNA sequences, of which 2,741 were for the ITS region. Certain species are deeply represented, with over 100 ITS sequences submitted: $P$. capsici $(n$ $=199), P$. cactorum $(n=176), P$. cinnamomi $(n=166), P$. nicotianae $(n=163)$, . cryptogea $(n=152), P$. infestans $(n=146)$, and $P$. citricola $(n=146)$. Some of the species counts are inflated because several species look alike, such as those in the P. citiricola complex that have recently been split into several species, including $P$. plurivora, P. multivora, and P. citricola (21). However, most species are represented only once and many sequences are from undescribed or poorly characterized species. GenBank is not actively curated in regards to correct identification of isolates associated with submitted sequences. Thus, problems exist for sequences deposited of incorrectly identified species. There is a need for a reliable, curated database for Phytophthora spp. identification.

Recently, a Phytophthora database (accessible at http://www. phytophthoradb.org/) was established to provide a tool for Phytophthora spp. identification and monitoring (30). This database is a valuable resource for Phytophthora biologists because it includes (as of 19 October 2010) over 4,650 sequences for upward of 2,400 isolates belonging to 106 Phytophthora spp. Currently, the database includes data for nine nuclear sequence loci, including the ITS region and the mitochondrially encoded cytochrome oxidase 2 gene (cox2) and the spacer region between coxl and cox2. This database houses information for populations of different Phytoph- thora spp. and provides tools for phylogenetic tree building, generation of virtual restriction patterns for species of interest, and BLAST analysis for species identification.

The nuclear ribosomal RNA (rRNA) genes (small subunit, large subunit, and 5.8S) are organized in a cluster but separated by two ITS regions (ITS1 and ITS2; Fig. 1A). Typically, in eukaryotic genomes, the rRNA genes are repeated in tandem arrays in the order of several hundred or, possibly, thousands of copies (20). The spacer regions ITS1 and ITS2 that are transcribed but not translated are more variable than the actual rRNA genes. The spacer regions diverge rapidly enough to be informative in distinguishing most (but not all) Phytophthora spp. (4).

The cytochrome c oxidase subunit 1 and 2 genes ( $\operatorname{cox} 1$ and $\operatorname{cox} 2$, respectively) are present as a gene cluster on the mitochondrial chromosome in Phytophthora (as well as in Pythium and many plant species; 27) (Fig. 1B). Due to interspecific sequence variation, the spacer region between these two genes is useful for development of species-specific markers $(29,34)$ as well as for sequence-based identification of many species (F. Martin, unpublished). One advantage of using this region for species identification is that it can be directly amplified from infected plant tissue as part of the Phytophthora genus-specific amplicon commonly used in a conventional PCR diagnostic assay for this genus (23), thereby eliminating the need for culturing and DNA extraction before BLAST analysis.

With creation of www.Phytophthora-ID.org, our objective was to provide a simple yet robust site that is easy to use and based on both the ITS and cox spacer regions. The cox spacer region was included because this locus encompasses a genus-specific amplicon used in molecular diagnostics for Phytophthora (23) and exhibits suitable interspecific variation to be useful for development of species-specific markers. We developed a database of sequences that is regularly updated to be selective for sequence accessions that come from trusted sources. We also validated the database

A

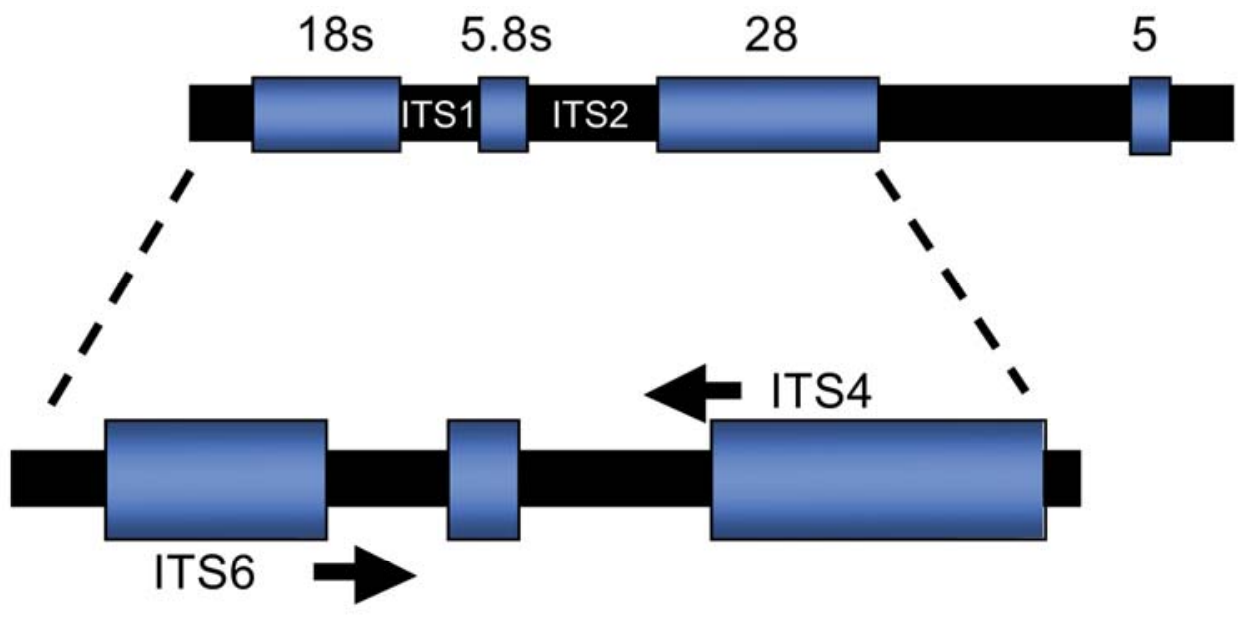

B

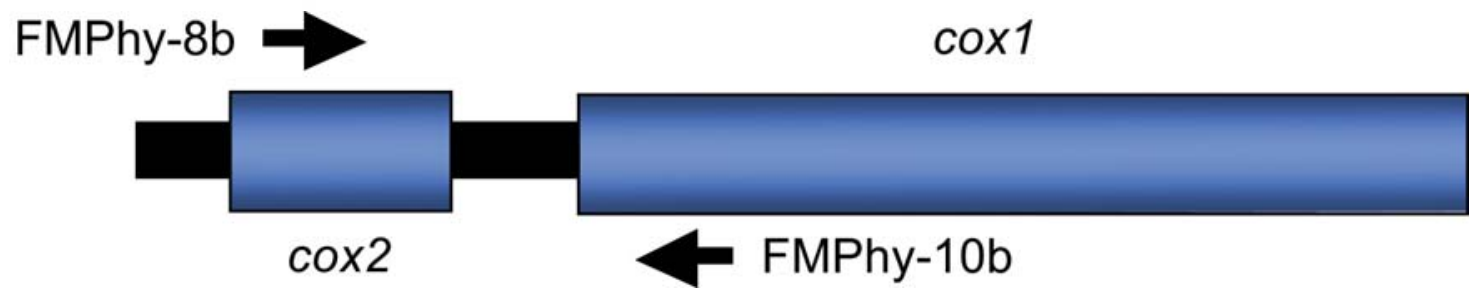

Fig. 1. Diagrammatic representation of the $\mathbf{A}$, internal transcribed spacer (ITS) and $\mathbf{B}$, cytochrome oxidase (cox) spacer regions in Phytophthora spp. The ITS region is polymerase chain reaction amplified using primers ITS4 and ITS6 whereas the cox spacer region is amplified using primers FMPhy-8b and FMPhy-10b. 
using an extensive sample of Phytophthora spp. The purpose of this article is to report on progress in the development of Phytophthora-ID and the validation of its data sets using an extensive sample of Phytophthora spp. It is expected that Phytophthora-ID will also help in development and maintenance of culture collections (22).

\section{Materials and Methods}

Phytophthora-ID content and implementation. PhytophthoraID provides a web-based platform for sequence-based BLAST searches against two regularly updated sequence databases. The two databases available in FASTA format (see http://www.ncbi.nlm. nih.gov/BLAST/fasta.shtml) include the ITS region sequences and the coxl and -2 spacer region. The web deployment of the database was accomplished using the Personal Sequence Database (14).

Both data sets presented on the Phytophthora-ID website list only sequences that are associated with (i) a published Phytophthora spp. description; (ii) the Phytophthora phylogenetics references by Cooke et al. (4), Martin and Tooley (28), and Blair et al. (2); or (iii) in the case of the cox spacer region, from isolates resequenced for this effort (F. Martin, unpublished). Further, novel taxa tentatively named are selectively included and labeled as $P$. taxon ' $\mathrm{X}$ '; as in, for example, $P$. taxon "asparagi". Some cox spacer sequences are currently unpublished and in preparation for publication. The complete list of ITS sequences, cox spacer sequences, GenBank accession numbers, and Phytophthora spp. included can be downloaded at www.Phytophthora-ID.org or as supplements (Supplementary Tables 1 and 2).
Species for which several nonidentical sequences exist are also included in the database. However, identical sequences for different isolates of the same species are excluded to avoid redundancy. For some species, neither ITS sequences nor voucher specimens were available; these species were generally described before the molecular era and, thus, could not be included. The broad species diversity sampled, including all known ITS sequences for Phytophthora spp. described to date, is shown in Figure 2.

PCR reactions and sequencing. PCR reactions for the ITS or cox spacer regions were conducted using either purified DNA or directly from a mycelial tuft lifted off a colony. For the ITS sequencing, genomic DNA was extracted from mycelia using the FastDNA SPIN kit (MP Biomedicals, LLC, Solon, OH) (18) whereas, for the cox spacer region, DNA was isolated as previously described (1). Mycelial tufts were obtained by scraping along the surface of a plate (1 to $2 \mathrm{~cm}$ ) toward the margins of a growing culture where sporangia were present and lifting hyphae using a sterile, dry toothpick. The mycelial tuft was then placed into a $100-\mu \mathrm{l}$ PCR tube containing distilled water and heated to $95.9^{\circ} \mathrm{C}$ for 5 min. PCR reactions were conducted on ABI 9700 or Verity thermocyclers (Applied Biosystems Inc., Foster City, CA) under the PCR conditions and protocols presented below. Amplicons were stored at $-20^{\circ} \mathrm{C}$ until sequenced. PCR amplicons of the ITS region were sequenced in forward and reverse at the Center for Genome Research and Biocomputing (Oregon State University, Corvallis) on an ABI 3730 capillary sequencer using standard reagents (Applied Biosystems Inc.). The cox spacer sequences were generated in both directions at the Pennsylvania State

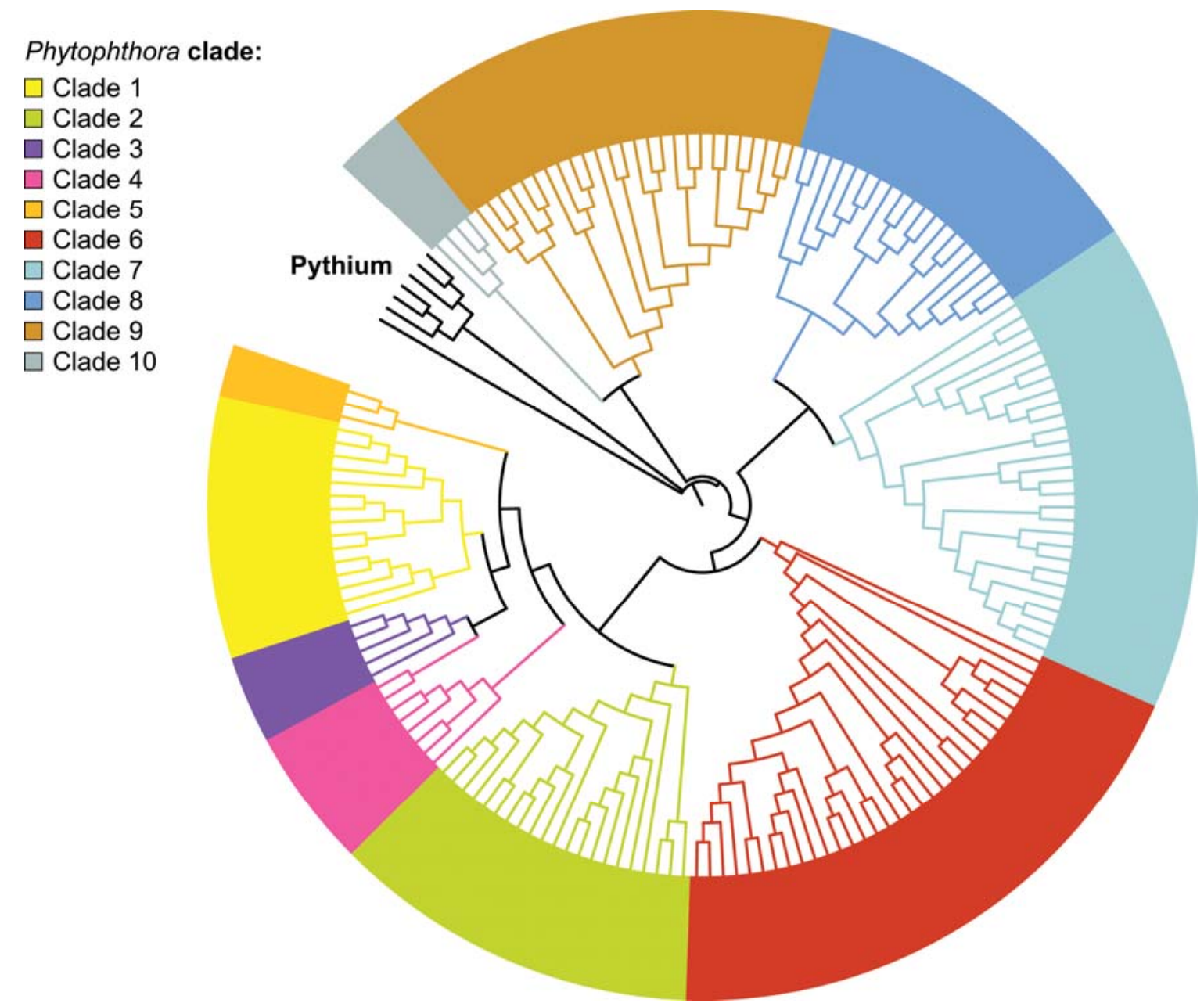

Fig. 2. Dendrogram showing the full clade diversity included in Phytophthora-ID. Dendrogram was constructed using all internal transcribed spacer (ITS) sequences contained in Phytophthora-ID after automated alignment using Clustal-W (33) followed by neighbor joining and rooting the tree with several Pythium outgroups. The tree was created using the Interactive Tree of Life (25). Note that this tree only depicts diversity and is not meant to replace a proper phylogenetic analysis as presented, for example, in Blair et al. (2). 
University's Huck Institute Nucleic Acid Facility (University Park) using the same techniques.

ITS amplification. Primers ITS4 and ITS6 were used for amplification of the ITS region in Phytophthora spp. as described previously (4,8,35; Fig. 1A). Amplification reactions were conducted in

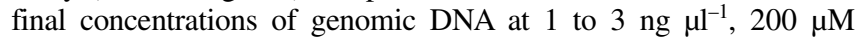
dNTP $(2.0 \mathrm{mM}), 0.4 \mu \mathrm{M}$ ITS6 and ITS4 primers, $1 \times$ Taq buffer (including $15 \mathrm{mM} \mathrm{MgCl}_{2}$ ), and Taq polymerase (Genscript
Corporation, Piscataway, NJ) at 0.05 unit $/ \mu$ l. PCR conditions were as follows: 1 cycle at $94^{\circ} \mathrm{C}$ for $3 \mathrm{~min}$; 35 cycles for $1 \mathrm{~min}$ of annealing at $55^{\circ} \mathrm{C}, 1 \mathrm{~min}$ of extension at $72^{\circ} \mathrm{C}$, and $1 \mathrm{~min}$ of denaturation at $94^{\circ} \mathrm{C}$; and, followed by 1 extension cycle at $72^{\circ} \mathrm{C}$ for 10 min. Phytophthora spp. typically yield PCR products in the range of 722 to $914 \mathrm{bp}$.

cox Spacer amplification. Sequences used as the basis for BLAST analysis of the cox spacer region were generated as part of
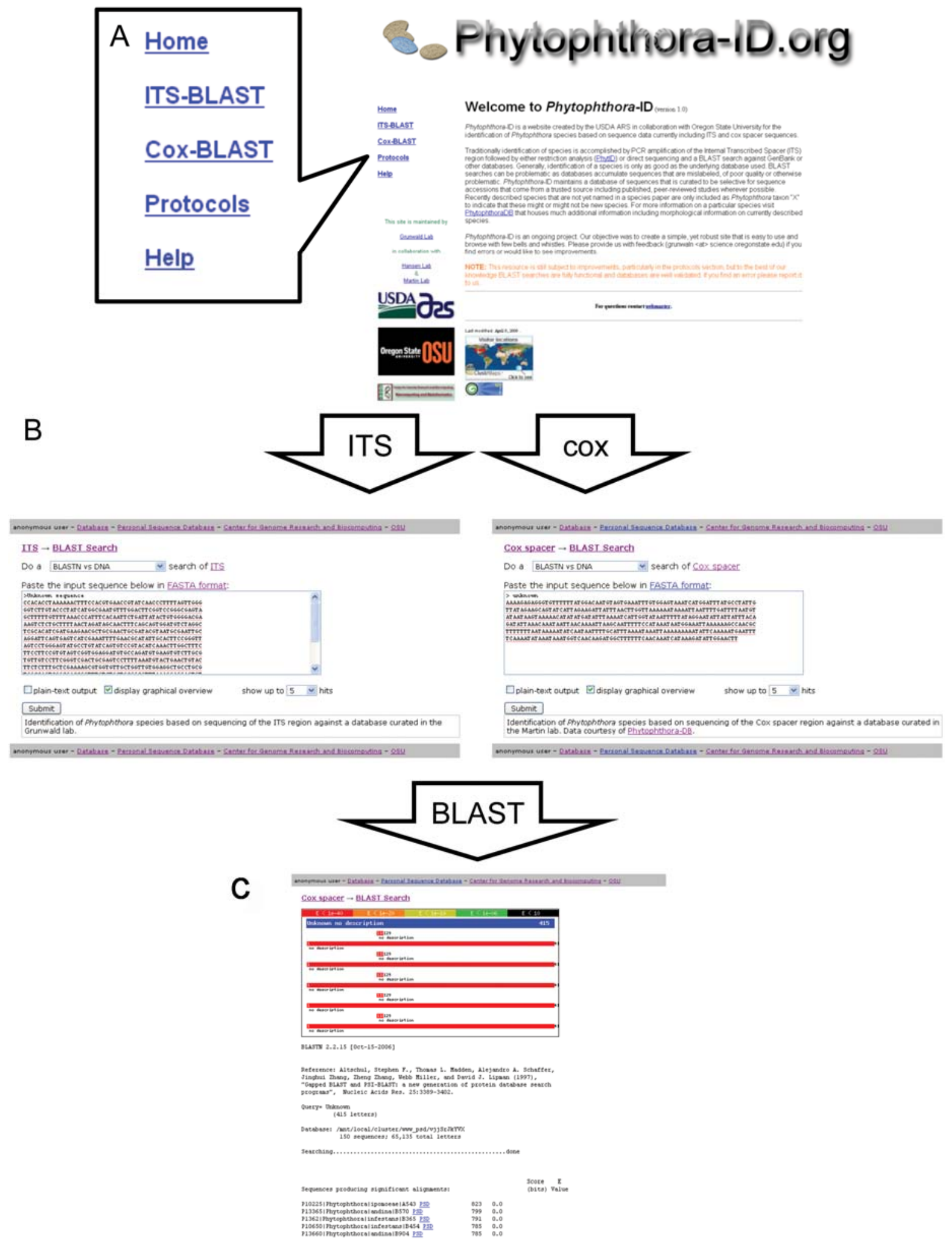

Fig. 3. Composite screen shots displaying general features of Phytophthora-ID and a generic workflow. A, Use menu on the left to choose either internal transcribed spacer (ITS) or cytochrome oxidase (cox) spacer region BLAST window. Protocols for polymerase chain reaction and help for interpretation of BLAST results are provided in the menu. B, Paste query sequence into window, choose graphical or plain text output and number of hits to display, and submit BLAST search. C, Interpret BLAST search results. 
the Phytophthora database project in the course of sequencing the cox 2 gene for phylogenetic analysis of the genus (F. Martin and M. D. Coffey, unpublished). The majority of the cox 2 gene, the spacer region, and the $5^{\prime}$ end of the cox 1 gene were amplified using primers FM35 and Phy-10b, with nested primers FM79 and FM80 used for sequencing the spacer region and flanking coding regions $(26,28,29)$. For amplification of the genus-specific amplicon from either plant samples or purified pathogen DNA, the primers FMPhy-8b and FMPhy-10b were used (29; Fig. 1B). Amplification reactions were conducted in final concentrations of genomic DNA

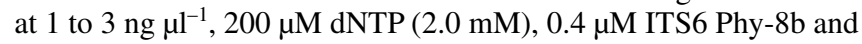
Phy-10b primers, $2 \%$ glycerol, $3 \mathrm{mM} \mathrm{MgCl}_{2}, 1 \times$ buffer, and AmpliTaq polymerase (Applied Biosystems) at 0.05 unit/ $\mu$ l. PCR conditions were as follows: 1 cycle of denaturation at $95^{\circ} \mathrm{C}$ for 3 min; 35 cycles of $1 \mathrm{~min}$ at $95^{\circ} \mathrm{C}, 1 \mathrm{~min}$ of annealing at $65.5^{\circ} \mathrm{C}$, and $1 \mathrm{~min}$ of extension at $72^{\circ} \mathrm{C}$; followed by 1 extension cycle at $72^{\circ} \mathrm{C}$ for 5 min. Phytophthora spp. typically yield PCR products in the range of $450 \mathrm{bp}$.

When doing amplifications from infected plant tissue, the concentration of pathogen DNA relative to plant DNA can be very low, and two rounds of amplification may be necessary to get enough template to clearly visualize on a gel (23). The first-round amplification can be diluted 1:100 and the amplification repeated without the addition of glycerol to the master mix and using a $64^{\circ} \mathrm{C}$ annealing temperature. Additional details on amplification and sequencing of this region from infected plant tissue can be found in the molecular diagnostics section of the Phytophthora Database (www.phytophthoradb.org).

Application of Phytophthora-ID to nursery samples. Phytophthora-ID was validated using an extensive Phytophthora sampling effort in commercial nurseries. Phytophthora cultures used to evaluate the database were maintained on cleared $10 \% \mathrm{~V} 8$ agar medium ( $100 \mathrm{ml}$ of $\mathrm{V} 8$ juice, $2 \mathrm{~g}$ of $\mathrm{CaCO}_{3}, 30 \mathrm{mg}$ of $\beta$-sitosterol, $15 \mathrm{~g}$ of agar, and $900 \mathrm{ml}$ of deionized water) in a $20^{\circ} \mathrm{C}$ incubator in the dark as described previously. We used Phytophthora-ID to identify Phytophthora spp. collected in nursery environments during 2006 to 2009 based on ITS sequencing. Species were isolated from different nursery crops, mostly Rhododendron, Viburnum, Pieris, and Kalmia spp., but also potting mix, soil, and irrigation and pond water. In total, 700 isolates were collected from four commercial ornamental nurseries in Oregon.

Use of database and interpretation of search results. To use Phytophthora-ID, sequences for a given isolate in FASTA format are submitted for BLAST searching at either the ITS or cox spacer BLAST window (Fig. 3A). Users can specify whether they want to have plain-text output or graphical output as well as the number of top hits (Fig. 3B). After submission, Phytophthora-ID returns a BLAST result window (Fig. 3C).

DNA-based Phytophthora spp. identification is an iterative process that, at times, requires further work and might include consideration of morphological traits. Interpretation of sequence reads and BLAST results requires experience. Generally, the best match shown at the top is the best estimate of species identity, although care has to be taken when interpreting these results. The scores derived from BLAST analysis can be influenced by length of coverage as well as sequence identity; therefore, it is important to look for nearly complete query coverage with very high sequence identity and a very low E value. Generally, when sequences are $100 \%$ identical, then the Phytophthora sp. has been identified. If identity is $<100 \%$ but $\geq 99 \%$, a putative match was made, and it is suggested that follow-up identification of key morphological characters using microscopy be conducted. If identity is $<99 \%$, a new species might be detected and additional work will be required. In this case, sequencing of the cox spacer region and BLAST search in Phytophthora-ID is suggested, followed by sequencing of additional loci and searching of PhytophthoraDB (30). It is important to recognize that one locus is not always suitable for identification of all species; low levels of sequence divergence may be observed among phylogenetically closely related species and differentiation to a species level may be further complicated due to intraspecific variation. Therefore, use of multiple loci will often improve the accuracy of identification.

Drawing conclusions from a BLAST analysis can be challenging for some species because several scores can be obtained for the same species or multiple species can be encountered with the same score, thus complicating species identification. A good example of this was found with some closely related clade 8 species in a recent evaluation of ITS (over 300 isolates) and $\operatorname{cox} 2$ gene sequences. Although the ITS data could clearly distinguish $P$. drechsleri from $P$. cryptogea, it could not differentiate among P. cryptogea, $P$. erythroseptica, and $P$. richardiae. This was due to intraspecific variation among these closely related species providing an overlap in sequence identity scores among species. Conversely, the cox2 gene data could separate all these species, highlighting the importance of using multiple loci for final isolate identification. Therefore, using multiple loci can often improve the accuracy of identification. Another approach for reducing the impact of intraspecific variation on species identification is selectively using only those portions of the ITS region that are highly conserved on an intraspecific level in the BLAST analysis, thereby eliminating the potential for obtaining overlapping scores (6).

Validation of database. During validation of Phytophthora-ID, Phytophthora isolates collected from four commercial nurseries could be unambiguously identified to species where species were known. Nurseries were dominated by a few species, including $P$. plurivora, $P$. cinnamomi, $P$. syringae, the poorly characterized species complex $P$. sp. PgChlamydo, $P$. citrophthora, and $P$. cryptogea (Fig. 4). P. gonapodyides was routinely retrieved from irrigation water.

\section{Conclusions}

Phytophthora-ID is a user-friendly, simple, and robust tool for identification of Phytophthora spp. Phytophthora-ID is complementary to the Phytophthora database (30) and, in fact, used carefully selected data for the cox spacer and ITS regions that we selectively resequenced from that resource to populate the databases. The unique contribution of Phytophthora-ID is that the underlying sequence databases used for BLAST searches were carefully assembled from trusted sources and will continue to be curated to ensure accuracy.

Some similar databases are in existence. For example, Unite provides a resource for identification of fungi (1). Fusarium-ID provides a resource for Fusarium spp. identification (13). PhytophthoraDB provides a parallel resource to Phytophthora-ID housing sequence data at both the intra- and interspecific level for Phytophthora spp. (30). Sequences for new species can be added to Phytophthora-ID upon request to the authors, who will decide if sequences will be deposited. Generally, only newly described species accompanied by a peer-reviewed publication or tentative,

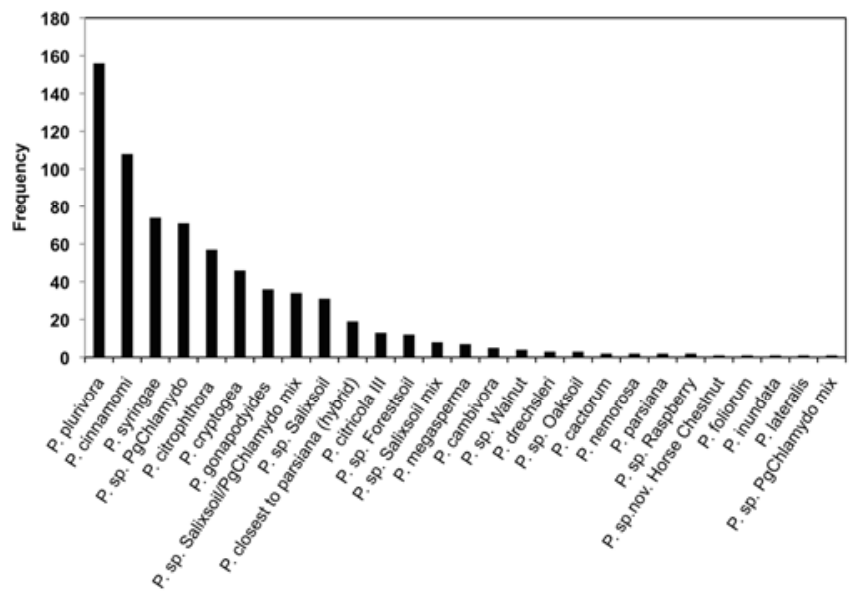

Fig. 4. Frequency of 700 Phytophthora spp. identified during a survey of four commercial Oregon nurseries conducted during 2006 to 2009. 
novel taxa (labeled temporarily as $P$. taxon " $\mathrm{X}$ " until published) will be added to this resource. There also exist databases at the intraspecific level housing genotypic information for certain species such as $P$. infestans $(9)$ and $P$. ramorum $(15,16)$.

Phytophthora-ID is an ongoing project that the authors will continue to update regularly. Both the ITS and cox spacer databases can be downloaded. Sequences for newly discovered species will be included as the literature expands. Authors are encouraged to submit sequences, DNA, or cultures for novel species to the lead author.

\section{Acknowledgments}

This work was supported in part by funds from USDA-ARS CRIS Project 5358-22000-034-00D, the USDA-ARS Floriculture Nursery Initiative, and the U.S. Forest Service Pacific Southwest Research Station. Sequencing of the cox spacer regions was supported by funds from the USDA-NRI Plant Biosecurity program, award 2005-35605-15393. We thank D. Gent and T. Peever for helpful comments and the Center for Genome Research and Biocomputing at Oregon State University for housing the server currently hosting PhytophthoraID.

\section{Literature Cited}

1. Abarenkov, K., Nilsson, R. H., Larsson, K.-H., Alexander, I. J., Eberhardt, U., Erland, S., Høiland, K., Kjøller, R., Larsson, E., Pennanen, T., Sen, R., Taylor, A. F. S., Tedersoo, L., Ursing, B. M., Vrålstad, T., Liimatainen, K., Peintner, U., and Kõljalg, U. 2010. The UNITE database for molecular identification of fungi-recent updates and future perspectives. New Phytol. 186:281-285.

2. Blair, J. E., Coffey, M. D., Park, S.-Y., Geiser, D. M., and Kang, S. 2008. A multi-locus phylogeny for Phytophthora utilizing markers derived from complete genome sequences. Fungal Genet. Biol. 45:266-277.

3. Brasier, C. 2007. Phytophthora biodiversity: how many Phytophthora species are there? Pages 101-115 in: Proc. Fourth Meet. Int. Union For. Res. Organ. (IUFRO) Working Party S07.02.09: Phytophthoras in Forest and Natural Ecosystems E. M. Goheen and S. J. Frankel, eds. U.S. Dep. Agric. For. Serv., Pacific Southwest Research Station, Monterrey, CA.

4. Cooke, D. E. L., Drenth, A., Duncan, J. M., Wagels, G., and Brasier, C. M. 2000. A molecular phylogeny of Phytophthora and related oomycetes. Fungal Genet. Biol. 30:17-32.

5. Drenth, A., Wagels, G., Smith, B., Sendall, B., O'Dwyer, C., Irvine, G., and Irwin, J. A. G. 2006. Development of a DNA-based method for detection and identification of Phytophthora species. Australas. Plant Pathol. 35:147159.

6. Druzhinina, I. S., Kopchinskiy, A. G., Komon, M., Bissett, J., Szakacs, G., and Kubicek, C. P. 2005. An oligonucleotide barcode for species identification in Trichoderma and Hypocrea. Fungal Genet. Biol. 42:813-828.

7. Erwin, D. C., and Ribeiro, O. K. 1996. Phytophthora Diseases Worldwide. American Phytopathological Society, St. Paul, MN.

8. Flier, W. G., Grünwald, N. J., Kroon, L. P. N. M., van den Bosch, T. B. M., Garay-Serrano, E., Lozoya Saldaña, H., Bonants, P. J. M., and Turkensteen, L. J. 2002. Phytophthora ipomoeae, a new homothallic species causing late blight on Ipomoeae longipedunculata in the Toluca Valley of central Mexico. Mycol. Res. 106:848-856.

9. Forbes, G. A., Goodwin, S. B., Drenth, A., Oyarzun, P., Ordoñez, M. E., and Fry, W. E. 1988. A global marker database for Phytophthora infestans. Plant Dis. 82:811-818.

10. Fry, W. E. 2008. Phytophthora infestans: the plant (and R gene) destroyer. Mol. Plant Pathol. 9:385-402.

11. Fry, W. E., and Goodwin, S. B. 1997. Re-emergence of potato and tomato late blight in the United States. Plant Dis. 81:1349-1357.

12. Galindo, J., and Hohl, H. R. 1985. Phytophthora mirabilis, a new species of Phytophthora. Sydowia 38:87-96.

13. Geiser, D. M., Jimenez-Gasco, M. D., Kang, S. C., Makalowska, I., Veeraraghavan, N., Ward, T. J., Zhang, N., Kuldau, G. A., and O'Donnell, K. 2004. FUSARIUM-ID v. 1.0: A DNA sequence database for identifying Fusarium. Eur. J. Plant Pathol. 110:473-479.

14. Givan, S., Sullivan, C., and Carrington, J. 2007. The Personal Sequence Database: a suite of tools to create and maintain web-accessible sequence databases. BMC Bioinf. 8:479.

15. Goss, E. M., Larsen, M., Chastagner, G. A., Givens, D. R., and Grunwald, N. J. 2009. Population genetic analysis infers migration pathways of Phytophthora ramorum in US nurseries. PLoS Pathog. 5:e1000583.

16. Grünwald, N. J., Goss, E. M., Ivors, K., Garbelotto, M., Martin, F. N., Prospero, S., Hansen, E., Bonants, P. J. M., Hamelin, R. C., Chastagner, G., Werres, S., Rizzo, D. M., Abad, G., Beales, P., Bilodeau, G. J., Blomquist, C. L., Brasier, C., Brière, S. C., Chandelier, A., Davidson, J. M., Denman,
S., Elliott, M., Frankel, S. J., Goheen, E. M., de Gruyter, H., Heungens, K. James, D., Kanaskie, A., McWilliams, M. G., Man in 't Veld, W., Moralejo, E., Osterbauer, N. K., Palm, M. E., Parke, J. L., Sierra, A. M. P., Shamoun, S. F., Shishkoff, N., Tooley, P. W., Vettraino, A. M., Webber, J., and Widmer, T. L. 2009. Standardizing the nomenclature for clonal lineages of the sudden oak death pathogen, Phytophthora ramorum. Phytopathology 99:792795 .

17. Grünwald, N. J., Goss, E. M., and Press, C. M. 2008. Phytophthora ramorum: a pathogen with a remarkably wide host-range causing sudden oak death on oaks and ramorum blight on woody ornamentals. Mol. Plant Pathol. 9:729-740.

18. Grünwald, N. J., Kitner, K., McDonald, V., and Goss, E. M. 2008. Susceptibility in Viburnum to Phytophthora ramorum. Plant Dis. 92:210-214.

19. Hardham, A. R. 2005. Phytophthora cinnamomi. Mol. Plant Pathol. 6:589604.

20. Hillis, D. M., Moritz, C., and Mable, B. K. 1996. Molecular Systematics. Sinauer Associates, Inc., Sunderland, MA.

21. Jung, T., and Burgess, T. I. 2009. Re-evaluation of Phytophthora citricola isolates from multiple woody hosts in Europe and North America reveals a new species, Phytophthora plurivora sp nov. Persoonia 22:95-110.

22. Kang, S., Blair, J. E., Geiser, D. M., Khang, C.-H., Park, S.-Y., Gahegan, M., O'Donnell, K., Luster, D. G., Kim, S. H., Ivors, K. L., Lee, Y.-H., Lee, Y.-W., Grünwald, N. J., Martin, F. M., Coffey, M. D., Veeraraghavan, N., and Makalowska, I. 2006. Plant pathogen culture collections: it takes a village to preserve these resources vital to the advancement of agricultural security and plant pathology. Phytopathology 96:920-925.

23. Kang, S., Mansfield, M. A., Park, B., Geiser, D. M., Ivors, K. L., Coffey, M. D., Grünwald, N. J., Martin, F. N., Lévesque, C. A., and Blair, J. E. 2010. The promise and pitfalls of sequence-based identification of plant-pathogenic fungi and oomycetes. Phytopathology 100:732-737.

24. Kroon, L. P. N. M., Bakker, F. T., van den Bosch, G. B. M., Bonants, P. J. M., and Flier, W. G. 2004. Phylogenetic analysis of Phytophthora species based on mitochondrial and nuclear DNA sequences. Fungal Genet. Biol. 41:766-782.

25. Letunic, I., and Bork, P. 2007. Interactive Tree Of Life (iTOL): an online tool for phylogenetic tree display and annotation. Bioinformatics 23:127128.

26. Martin, F. N. 2000. Phylogenetic relationships among some Pythium species inferred from sequence analysis of the mitochondrially encoded cytochrome oxidase II gene. Mycologia 92:711-727.

27. Martin, F. N., Bensasson, D., Tyler, B. M., and Boore, J. L. 2007. Mitochondrial genome sequences and comparative genomics of Phytophthora ramorum and P. sojae. Curr. Genet. 51:285-296.

28. Martin, F. N., and Tooley, P. W. 2003. Phylogenetic relationships among Phytophthora species inferred from sequence analysis of mitochondrially encoded cytochrome oxidase I and II genes. Mycologia 95:269-284.

29. Martin, F. N., Tooley, P. W., and Blomquist, C. 2004. Molecular detection of Phytophthora ramorum, the causal agent of sudden oak death in California, and two additional species commonly recovered from diseased plant material. Phytopathology 94:621-631

30. Park, J., Park, B., Veeraraghavan, N., Jung, K., Lee, Y.-H., Blair, J. E., Geiser, D. M., Isard, S., Mansfield, M. A., Nikolaeva, E., Park, S.-Y., Russo, J., Kim, S. H., Greene, M., Ivors, K. L., Balci, Y., Peiman, M., Erwin, D. C., Coffey, M. D., Rossman, A., Farr, D., Cline, E., Grünwald, N. J., Luster, D. G., Schrandt, J., Martin, F., Ribeiro, O. K., Makalowska, I., and Kang, S. 2008. Phytophthora database: a forensic database supporting the identification and monitoring of Phytophthora. Plant Dis. 92:966-972.

31. Rizzo, D. M., Garbelotto, M., and Hansen, E. M. 2005. Phytophthora ramorum: integrative research and management of an emerging pathogen in California and Oregon forests. Annu. Rev. Phytopathol. 43:309-335.

32. Schena, L., and Cooke, D. 2006. Assessing the potential of regions of the nuclear and mitochondrial genome to develop a "molecular tool box" for the detection and characterization of Phytophthora species. J. Microbiol. Methods 67:70-85.

33. Thompson, J., Higgins, D., and Gibson, T. 1994. CLUSTAL W: improving the sensitivity of progressive multiple sequence alignment through sequence weighting, positions-specific gap penalties and weight matrix choice. $\mathrm{Nu}$ cleic Acids Res. 22:4673-4680.

34. Tooley, P. W., Martin, F. N., Carras, M. M., and Frederick, R. D. 2006. Real-time fluorescent polymerase chain reaction detection of Phytophthora ramorum and Phytophthora pseudosyringae using mitochondrial gene regions. Phytopathology 96:336-345.

35. White, T. J., Bruns, T., Lee, S., and Taylor, J. 1990. Amplification and direct sequencing of fungal ribosomal RNA genes for phylogenetics. Pages 315322 in: PCR Protocols: A Guide to Methods and Applications. M. A. Innis, D. H. Gelfand, J. J. Sninsky, and T. J. White, eds. Academic Press, San Diego, CA 